\title{
Migración, miedos y medios en la elección presidencial en Chile (2017)
}

\author{
DOI: https://doi.org/10.18046/recs.i31.3730 \\ Migration, Fears and the Media in the Presidential \\ Election in Chile (2017) \\ Lucía Dammert ${ }^{* *}$ \\ Universidad de Santiago de Chile (Santiago de Chile, Chile) \\ Matthias Erlandsen ${ }^{* * *}$ \\ Pontificia Universidad Católica de Chile (Santiago de Chile, Chile)
}

\footnotetext{
* El presente artículo se realizó con el apoyo del Fondo Nacional Científico y Tecnológico. Proyecto Fondecyt 11180438, "Legitimidad y confianza pública de las instituciones policiales en Chile". Se agradece el apoyo de Jennifer Morgado Mancilla, Andrea Escobar Hernández, Lucas Paredes y Katya Olea en el desarrollo del proyecto. Artículo de investigación recibido el 29.09.2019 y aceptado el 21.02.2020.

** Doctora en Ciencia Política por la Universidad de Leiden (Holanda). Magíster en Desarrollo Urbano y Regional de la Universidad de Pittsburgh (Estados Unidos). Socióloga de la Universidad Nacional de Cuyo (Argentina). Correo electrónico: lucia.dammert@usach.cl ORCID: https://orcid.org/oooo-ooo3-1239-4425

${ }^{* * *}$ Estudiante de Doctorado en Ciencias de la Comunicación de la Pontificia Universidad Católica de Chile (Chile). Magíster en Estudios Internacionales de la Universidad de Chile (Chile). Periodista de la Pontificia Universidad Católica de Chile (Chile). Correo electrónico: merlandsen@uc.cl ORCID: https://orcid.org/oooo-ooo1-9791-472X
} 


\section{Cómo citar/How to cite}

Dammert, Lucía; Erlandsen, Matthias (2020). Migración, miedos y medios en la elección presidencial en Chile (2017). Revista CS, 31, 43-76. https://doi.org/10.18046/recs.i31.3730 


\section{Resumen}

La migración se ha instalado como el otro amenazante en América Latina, y Chile no es una excepción. Tomando la conceptualización de la comunidad imaginada, el artículo analiza la importancia y características de la cobertura de medios de prensa sobre migración y el populismo punitivo durante la elección presidencial de Chile, en 2017. Se analizó una muestra aleatoria de todas las piezas informativas de los dos principales diarios durante el año 2017. La migración se ha convertido en un tema de debate nacional y los medios muestran un discurso político centrado en el populismo punitivo, la innecesaria generalización de imágenes estigmatizadoras y la consolidación de la metáfora que vincula la migración con el peligro, principalmente la criminalidad. Más crónica que análisis, es la principal característica de las coberturas que permiten enfatizar imágenes amenazantes y políticamente rentables, posiblemente tratando de proteger esa comunidad que el discurso político realza de forma constante.

\section{PALABRAS CLAVE:}

migración, medios de comunicación, populismo punitivo, comunidad imaginada, Chile

Migration has been defined as the threatening other in Latin America; Chile is no exception. Based on the conceptualization of the imagined community, this article analyzes the importance and characteristics of press media coverage on migration and punitive populism in the framework of the Presidential election of 2017 in Chile. A random sample of all the informative pieces of the two main newspapers throughout 2017 was analyzed. Migration has become a topic of national debate. The media show a political discourse focused on punitive populism, the unnecessary generalization of stigmatizing images, and the consolidation of a metaphor that links migration with danger, mainly criminality. The more chronic-oriented than analysis-oriented characteristic of the coverage makes it possible to emphasize in the threatening and politically profitable images. Possibly trying to protect that community that the political discourse constantly highlights.

\section{KEYWORDS:}

Migration, Media, Punitive Populism, Imagined Community, Chile 



\section{Introducción}

Los miedos se han instalado en la forma como los latinoamericanos desarrollamos nuestra vida en comunidad. Múltiples son los estudios que ponen énfasis en el miedo al delito como principal emoción que impacta en el debate político y social, así como en la forma en que se desarrolla el debate político y se diseñan las principales respuestas gubernamentales frente al crimen (Dammert, 2012; Kessler, 2009).

El temor al delito se instala como una percepción de amenaza, a lo que consideramos es nuestra comunidad, marcada por una clara diferencia que instala a diversos colectivos considerados externos, los otros. El otro amenazante es un concepto flexible, que varía de acuerdo con lo que las comunidades, o sus élites, definen como lo más preocupante. En este artículo se analiza la importancia y características de la cobertura de medios de prensa sobre la migración y el desarrollo del populismo punitivo en el marco de la elección presidencial de Chile en 2017.

Se utilizó una técnica de análisis de contenidos mediante la aproximación inductiva a partir de la escala de encuadres noticiosos de la inmigración (ENI), propuesta por Igartua, Muñiz y Cheng (2005), adaptada para la realidad y actualidad chilena. Para esto, se analizaron todas las piezas informativas de las secciones más importantes de los diarios El Mercurio y La Tercera, principales medios de comunicación escrita del país. La investigación se desarrolló utilizando dos técnicas: por un lado, se seleccionaron seis semanas construidas empleando salto sistemático cada ocho días, partiendo por las ediciones impresas del 2 de enero de 2017, hasta las ediciones del 30 de septiembre de 2017, ambas fechas inclusive. Por otro lado, durante el período de campaña electoral se optó por una técnica de análisis censal para el lapso entre el 1 de octubre y el 31 de diciembre de 2017, es decir, trece semanas.

La migración se ha convertido en un tema de debate nacional. Los medios permanentemente muestran un discurso político centrado en el populismo punitivo, en la innecesaria generalización de imágenes estigmatizadoras y en la consolidación de una metáfora que vincula la migración con el desarrollo de acciones que ponen en peligro la comunidad, principalmente la criminalidad. Más crónica que análisis es la principal característica de las coberturas que permiten enfatizar imágenes amenazantes y políticamente rentables en un debate donde aún hay poco énfasis en la identificación de las diferencias, posiblemente tratando de proteger esa comunidad (o nación) que el discurso político realza de forma constante. 


\section{La comunidad imaginada}

El concepto de comunidad imaginada es clave para intentar caracterizar la identidad nacional, y las dinámicas producidas por fenómenos como la migración y el crimen (Anderson, 1993). Esta conceptualización se enmarca en el entendimiento de la nación como "una comunidad políticamente imaginada como inherentemente limitada y soberana" (Anderson, 1993: 23). Definición que tiene tres elementos principales. Primero, una comunidad es un grupo de personas que utilizan el mismo conjunto de recursos simbólicos cuando articulan su sentido de identidad (Finlayson, 2001).

\footnotetext{
"Independientemente de la desigualdad y la explotación [interna] que en efecto puedan prevalecer en cada caso, la nación se concibe siempre como un compañerismo profundo, horizontal", generando una fraternidad que ha permitido que en los últimos dos siglos millones de personas maten y estén dispuestas a morir por estas imaginaciones. (Anderson, 1993: 25)
}

Segundo, la comunidad es imaginada dado que los miembros de una misma nación no conocerán nunca a la mayoría de sus compatriotas, "pero en la mente de cada uno vive la imagen de su comunión" (Anderson, 1993: 23). Es decir, "se refiere a un grupo de personas, no inmediatamente tangible y accesible, con las que nos conectamos a través del poder de la imaginación" (Kanno; Norton, 2003: 241), que se extiende tanto en la espacialidad como en la temporalidad. Tercero, la nación se concibe como soberana, definida históricamente y protegida por el Estado (Anderson, 1993). Así, lo que hizo imaginables a las nuevas comunidades era una interacción semifortuita, pero explosiva, entre un sistema de producción y de relaciones productivas -el capitalismo-, una tecnología de las comunicaciones -el capitalismo impreso- y la fatalidad de la diversidad lingüística que permitió la creación de entidades centralizadas mucho más pequeñas que en tiempos previos (Anderson, 1993; Calhoun, 2017; Desai, 2008).

Esta conceptualización es utilizada desde una multiplicidad de perspectivas y contextos. Un ejemplo reciente es la concepción de ciertos nichos de los medios sociales y otros espacios de internet como comunidades imaginadas, ya que estos se pueden volver el locus de diferentes formas y escalas de comunión (Finlayson, 2001). Esto se refleja en subculturas que se forman alrededor de grupos cuyos miembros comparten un sentimiento de identidad, conexión y lazo afectivo en diversa intensidad.

Más allá de sus alcances, esta perspectiva no es carente de críticas. En primer lugar, se critica la definición de nación como comunidad fraternal y horizontal que, para diversos autores, es "otro mito de la modernidad creado para legitimar la hegemonía política de los sectores dominantes" (Sanjinés, 2007:300). De esta forma, 
podría oscurecer la experiencia de regiones como América Latina, donde los lazos entre diferentes sectores sociales no eran de camaradería, sino de dependencia (Lomnitz, 2001). En segundo lugar, se critica la separación del nacionalismo con el racismo, estableciendo una perspectiva dicotómica que "señala que la nación 'inspira amor', mientras que el racismo 'sueña eternamente en contaminaciones, ya que los sueños del racismo, en realidad, tienen su origen en ideologías de clase y no en la idea de nación"” (Treviño-Rangel; Hammeken, 2008: 675).

Sin embargo, esta afirmación en América Latina muestra una perspectiva distinta donde la raza ha sido un eje central de la definición de la nación. Así, por ejemplo, en México, "el racismo, la nación y el nacionalismo son conceptos que han evolucionado estrechamente vinculados", y donde una parte significativa de la población no solamente no ha sido incluida, sino que ha sido ignorada, excluida o eliminada de esa comunidad (Treviño-Rangel; Hammeken, 2008: 671). Lo mismo ocurre en Brasil, donde Lissovsky y De Matos (2018) señalan que hubo un consenso sobre que la población brasileña estaba formada por una mezcla de razas y que su destino sería alcanzado mediante la hegemonía de los blancos, particularmente los portugueses, cuyos derechos resultaron producto de su triunfo frente a los indígenas durante la conquista.

\section{Medios y miedos}

La construcción de la comunidad imaginada tiene un soporte central en el llamado capitalismo impreso "que a través de la novela y del periódico, permitió (...) que un número rápidamente creciente de personas pensaran acerca de sí mismos y se relacionaran con otros, en formas profundamente nuevas dado que permitieron que estas personas pudieran imaginarse viviendo una historia y un tiempo simultáneo" (Anderson, 1993: 63). Sin duda, las identidades nacionales son producidas, reproducidas y transformadas a través de discursos emitidos por diversos actores que se propagan principalmente a través de los sistemas educacionales y los medios de comunicación masiva (De Cillia; Reisigl; Wodak, 1999).

Históricamente, los medios de comunicación tienen un rol clave en la (re)mediación del proceso de imaginar y (re)imaginar la nación (Koh, 2005) en tanto forman, consolidan y dirigen la opinión pública. Sin embargo, es importante destacar que los mensajes mediales son más efectivos al confirmar o reforzar actitudes y creencias preexistentes, que cambiándolas. Como explica Thompson (2012:177), "alteraciones menores pueden ocurrir, pero la conversión fundamental de diferentes puntos de vista es escasa". Investigaciones más recientes, como las realizadas por Breuilly (2016) en África postcolonial, señalan que no hay evidencia de que el acceso a los medios haya tenido algún efecto en promover la identificación nacional. Eso sí, el 
excesivo énfasis en los cambios de actitud a corto plazo puede oscurecer un rango de influencias más sutiles de los mensajes provistos por los medios de comunicación.

De esta forma, los medios no solo reflejan experiencias nacionales, sino que son capaces de crearlas al ser quienes las transmiten. Estos eventos mediales "integran sociedades en un pálpito compartido y evocan una renovación de la lealtad a la sociedad y a su autoridad legítima" (Dayan; Katz, 1992). En el actual contexto de globalización cultural y de tecnologías de la información, son los eventos masivos, la radio e incluso productos culturales como las telenovelas, los que "están definiendo las pautas de adhesión nacional y las reconceptualizaciones en torno a la nación" (Uribe-Alvarado, 2005: 13), y muchas veces son el primer acercamiento que se tiene a la misma (Martín-Barbero, 1993). Por su parte, Silverstone (como se citó en Madianou, 2002) sugiere que se debe poner el foco en las noticias como un fenómeno social que se ha vuelto componente indispensable de la vida diaria, señalando que las noticias, en su carácter regular y diario, funcionan como una institución crucial en los procesos de mediación.

La inseguridad es un tema clave en la cobertura de medios de comunicación. Tradicionalmente enfocado desde la llamada página roja o policial, ha pasado a tener un rol principal en el debate político, social e incluso económico. Para la ciudadanía, los medios de comunicación son la principal fuente de información sobre hechos criminales y sus consecuencias, consolidando su papel en la percepción que se tiene sobre la temática. Sin duda, esta está fuertemente moldeada por la relación entre el consumo de medios de comunicación -tradicionales y emergentes- $y$ la selección de la realidad que ellos exponen, lo que se traduce en influencia sobre la opinión pública en diversas temáticas, incluyendo la migración (Bozda; Smets, 2017; Focas; Kessler, 2015; Gasper; Sinatti, 2016; Pyszcek, 2012).

El papel e impacto de los medios de comunicación sobre los temas de seguridad es analizado desde distintas perspectivas. La literatura tradicional vincula a los medios de comunicación con la percepción de las audiencias en materias de seguridad pública, miedo y crimen, en relación inversa a lo que reportan las estadísticas sobre la calidad de vida. Altheide (2003) analiza la prensa en Estados Unidos y concluye que, mientras los periódicos y los noticiarios de televisión están dominados por un discurso de miedo al crimen (que se traduce en alzas en las encuestas sobre percepción de sus niveles), los estadounidenses cada vez viven en mejores condiciones, más sanos y seguros en cualquier período previo de la historia. Diversos autores desarrollan un debate en torno a preguntas de índole retórica sobre la relación triangular entre la cobertura mediática de hechos criminales, la fascinación del público por esas noticias y las fluctuaciones en los indicadores de miedo al crimen, estableciendo que los medios de comunicación efectivamente generan un efecto 
sobre las audiencias, particularmente cuando se trata de la publicación de hechos de violencia, crimen y, en general, aquellas que concentran tonos negativos sobre la vida diaria de los ciudadanos (Dammert, 2012; Dammert; Sandoval, 2019; Ericson, 2007; Focas; Kessler, 2015; Galtung; Ruge, 1965; Hayward; Young, 2004; Östgaard, 1965).

Una perspectiva más crítica sobre los medios les otorga un rol crucial, dado que se considera que forman, consolidan y dirigen la opinión pública, situándose a sí mismos como la verdadera voz del pueblo (Dobrynina, 2016). Desde esta perspectiva, los medios tenderían a distorsionar la realidad de la situación criminal, ya que se guían por una lógica de mercado, y los delitos graves son los que más llaman la atención del público (Graber, 1980).

Adicionalmente, extensa evidencia empírica relaciona la difusión de violencia por parte de los medios con altos niveles de ansiedad en la sociedad (Bonner, 2018; Dammert, 2012; Slone, 2000). El sensacionalismo y sentimentalismo con el cual los medios presentan las noticias sobre crímenes ha convertido a la víctima en un representante de la sociedad, traduciendo su experiencia a una común y colectiva, en lugar de representar una experiencia individual y atípica (Smolej; Kivivuori, 2008). Generalmente, las noticias se concentran en el hecho delictual y lo que ocurre en una breve temporalidad posterior, quedando descontextualizado y desvinculado del proceso de justicia criminal. En estas coberturas -de los medios tradicionales-, se consultan opiniones y vocerías de actores políticos que ponen énfasis en las respuestas que se estén implementando o en las carencias. De hecho, las declaraciones altisonantes florecen y los actores políticos hacen uso de los problemas criminales sensacionales o populares para fortalecer su capital político y mantener apoyo electoral (Slone, 2000).

La cobertura sobre el fenómeno migratorio enfrenta una situación similar. Diversos estudios plantean que los medios juegan un papel central en la construcción de los migrantes como criminales, y justifican la aplicación de respuestas represivas hacia la migración (Cuevas-Calderón, 2019; Gerard; Pickering, 2013; Granero, 2018; Mountz, 2010; Sonderegger, 2017; Spena, 2014). Por otro lado, Brouwer, Van der Woude y Van der Leun (2017) postulan que, en el caso neerlandés, el proceso de criminalización de migrantes irregulares es bastante difuso, los medios parecieran seguir tendencias políticas en lugar de impulsar o provocarlas. En los EE. UU., un estudio reciente analizó una década de los encuadres más utilizados por los medios al referirse al debate acerca de la migración en cuatro campañas electorales, y encontró que en $42,5 \%$ de los casos se utilizó un encuadre de conflicto en el cual el problema se consideraba como de ellos vs. nosotros (Kim; Wanta, 2018).

En otro estudio sobre España, se analiza que, dada la situación de pánico moral respecto al crimen migrante, diversos políticos recurrieron al discurso populista 
utilizando los medios de comunicación para estigmatizar y criminalizar a un grupo migrante en específico (Soriano-Gatica; Peres-Neto, 2008). Otra investigación desarrollada en Inglaterra observó el impacto que han tenido los medios de comunicación sobre las percepciones de personas pertenecientes a distintas razas y pueblos originarios sobre los migrantes, encontrando que el uso de ciertas palabras e imágenes proporcionadas por los medios tenían una fuerte asociación con las opiniones y creencias de las personas. Por ejemplo, refugiados y solicitantes de asilo se convirtieron en términos genéricos para referirse a grupos con comportamientos desviados, y cuando los entrevistadores indagaban en cuanto a estas categorizaciones, los entrevistados retrataban imágenes que habían visto en los medios ilustrando situaciones de marginalidad social que involucraban a migrantes (Philo; Briant; Donald, 2013).

En el mismo pais, Nagarajan (2013) y The Migration Observatory (2013) cuantificaron y analizaron los periódicos entre 2010 y 2012, concluyendo que en $21,5 \%$ de los casos codificados, el adjetivo ilegal estaba relacionado con el sustantivo inmigrante, mientras que dentro en un rango de cinco palabras antes o después de inmigrantes, migrantes, refugiados o asilados, constantemente se encontraban palabras como criminales, ilegales o quedarse. Nagarajan (2013) es más enfática en establecer que el miedo, el odio y el rechazo hacia los migrantes, en los casos europeos observados, se deben a un uso político de los medios de comunicación. En su análisis, destaca que este encuadre empleado por políticos y medios de comunicación resulta en una fuerte demonización de las poblaciones migrantes, y responde únicamente a una estrategia de dividir para conquistar, en particular en contextos electorales, donde el discurso de racismo y xenofobia aumenta.

La situación es similar en contextos de países en vías de desarrollo. En Sudáfrica, un estudio concluyó que, en su gran mayoría, los reportajes acerca de la migración son altamente sensacionalistas, africanizados y negativos, y toman la forma de artículos superficiales que no informan al lector sobre las complejidades de la migración ni su vinculación con fenómenos sociales, políticos y económicos a nivel macro (Danso; McDonald, 2001). Otras investigaciones en ese mismo país afirman que la xenofobia se puede atribuir a la formulación y publicidad que se ha dado a los puntos de vista antimigratorios en los medios (Minnaar; Hough; De Kock, 1996).

Más allá de las características comunes del rol del capitalismo impreso en la construcción de la comunidad imaginada en la actualidad, existen otras experiencias. Así, por ejemplo, la comunidad migrante se ha declarado a sí misma en periódicos, programas de radio y hasta televisión, dejando claro que "la identidad no es una construcción monolítica, sino una discursiva que está en constante circulación que modifica y es modificada por otros discursos" (Melella, 2011: 1). 


\section{Construcción de el otro}

La comunidad imaginada no es necesariamente el espacio de fraternidad, compromiso y pertenencia que detallaba Anderson (1983). La construcción de el otro como amenaza es un fenómeno socialmente creado y transversal en nuestras sociedades. Muchos "parecen ser convencidos, usualmente por demagogos, que los outsiders son una amenaza, que los migrantes están robando sus empleos, o que los capitalistas extranjeros están socavando los negocios nacionales" (Calhoun, 2016: 14). No obstante, la noción misma de identidad está atravesada por la idea de un otro en torno al cual se define (Parekh, 1995). De hecho, la identidad nacional solo se vuelve significativa cuando se contrasta y se diferencia con otras (Triandafyllidou, 1998). Esta diferenciación se realiza con base en una serie de características que una comunidad tiene en común, como el lenguaje o las costumbres, que se ensalzan y muchas veces se sobreexageran para constituir su identidad, dejando a los otros al margen. La comunidad no es simplemente imaginada como una forma generalizada de existencia, sino en un tipo de comunidad en particular que encarna valores propios, produciendo un tipo específico de sujetos (Nash; Scott, 2008).

Históricamente, la población indígena y grupos de migrantes no blancos "representaban el 'otro' en la imagen de nación definida por la elite. Imagen que percibe a estos grupos foráneos se les percibe como una amenaza para su identidad" (Treviño-Rangel; Hammeken, 2008: 684). En la actualidad, los otros incluyen principalmente a la comunidad migrante que puede ser procesada en términos de diversidad -el reconocimiento de la otredad-o de división -la negación de la otredad-. En muchos casos, resulta que este grupo se ve representado como amenazante a la identidad nacional, lo que decanta en la propagación de una retórica basada en el lenguaje de amigo-enemigo que puede decantar en brotes de xenofobia y racismo o ser caldo de cultivo para retóricas populistas nativistas y nacionalistas (Sonderegger, 2017). La élite se reconoce como aquella que habla en nombre de la parte más profunda, verdadera, auténtica y merecedora de la nación (Ostiguy, 2009).

Al migrante se le llama " 'trabajador extranjero', 'minoría étnica', 'inmigrante no comunitario' o sencillamente 'moro' o 'negro' para anticiparle encima la figura con la que un día, con la que hoy, podremos expulsarlo, asimilarlo, excluirlo, ignorarlo" (Santamaría-Lorenzo, 2002: 60). Y, por otro lado, se espera que los migrantes puedan igualar o superar la productividad de los nacionales o si no son considerados como cargas sociales, especialmente si no tienen buena situación económica o altas calificaciones escolares y laborales, bajo la suposición de que su valor se vincula con su habilidad de enriquecer a la nación y ser un aporte (Dammert; Sandoval, 2019; Granero, 2018; Li, 2003). 
La insistencia y constante asociación de los migrantes con la diferencia, competencia y transgresión de normas y estándares ayuda a que se equipare discursivamente su presencia con alarmas sociales como la delincuencia, el tráfico de drogas o el terrorismo, ante las cuales la sociedad no puede más que precaverse o defenderse, siendo fácil demonizarlos como enemigos o clases peligrosas (Santamaría-Lorenzo, 2002). De esta forma, los otros significantes se vuelven salientes como chivo expiatorio en períodos de crisis social, política o económica, cuando la identidad de la nación o la legitimidad es puesta en cuestión (Doob, 1965).

\section{Populismo punitivo y crimigración}

El temor a la alteración de la comunidad imaginada y la amenaza de los otros trae de la mano el surgimiento de una retórica electoral y una práctica de política pública que tienden a endurecer sus posturas frente al crimen y la migración, dando lugar al desarrollo del populismo punitivo y la llamada crimigración (Dammert; Sandoval, 2019; Gerard; Pickering, 2013; Stumpf, 2006).

El populismo no es un fenómeno nuevo en América Latina, y se presenta principalmente como un proceso que le otorga voz a aquellos grupos de la ciudadanía que sienten que han sido ignorados por el gobierno (Pratt, 2007). Es decir, no tiene por objetivo representar a la ciudadanía en su totalidad, sino avanzar en las necesidades y urgencias de algunos segmentos (De Raadt; Hollanders; Krouwel, 2004).

La punitividad, por su parte, es un concepto que refiere a la presencia de actitudes públicas duras hacia las personas que delinquen. En las últimas décadas, la punitividad se ha visto incrementada frente al avance de la criminalidad, la sensación de impunidad y la percepción de ineficacia estatal (Dammert, 2019). Dos son las principales explicaciones teóricas sobre este proceso: en primer lugar, se interpreta como una reacción a la ansiedad que causa la incertidumbre del día a día en la economía global, en sociedades occidentales que han sentido los rápidos y desestabilizadores cambios socioeconómicos y morales de la modernidad tardía (Green, 2008); segundo, se relacionan las actitudes punitivas con miedos y preocupaciones vinculados a la descomposición moral y social asociada a esa misma modernidad (Tyler; Boeckmann, 1997).

El punitivismo, cuando se concentra en propuestas cuyo principal objetivo es movilizar votos, se torna en el llamado populismo punitivo (Bottoms, 1995). Es decir, propuestas que se basan en demandas sociales que se sienten desatendidas, muchas veces vinculadas con hechos escandalosos o de impunidad evidente, más que con una solución razonada y estudiada en materia criminal (Dobrynina, 2016). En este 
marco, el populismo punitivo no tiende a generar consensos, sino más bien a dividir la sociedad entre buenos y malos, criminales y víctimas, sospechosos y ciudadanos (Bonner, 2018; Dammert, 2019).

Por otro lado, la crimigración refiere a la convergencia entre el control del crimen y el control de la migración, y es una de las áreas que se está desarrollando más rápidamente (Stumpf, 2006). Este es un fenómeno transnacional que ha resultado en una cantidad inédita de deportaciones y detenciones, ha criminalizado a innumerables residentes no-ciudadanos y ha significado el desarrollo de una nueva categoría de crímenes que dependen más del estatus de la ciudadanía, que de la conducta. Este proceso de crimigración cambia la manera en que el público percibe el carácter y la contribución del migrante, desde una tolerancia forzada a los residentes no oficiales, a una cultura de terror por una sensación de invasión (Chacón, 2012; Parkin, 2013). La literatura muestra que la crimigración impacta en las percepciones acerca de los extranjeros, y sobre la migración en general. Esto se explica, en parte, a través de la teoría de la pertenencia, que aduce que la categorización como ilegales de aquellos que llegan sin documentación genera una relación con el derecho penal en el imaginario de las personas, haciéndoles entender que aquellos que llegan sin documentos y trabajan sin visa son criminales, peligrosos e indignos (Bosworth, 2008; Gasper; Sinatti, 2016; Pyszczek, 2012).

\section{El contexto chileno}

Desde la década de 1990, la migración en Chile ha visto aumentar sus cifras (Dammert; Sandoval, 2019). Si bien en el año 1991 representaba el o,8 \% de la población, la información al año 2017 estima que alcanza el 4,4 \% del total nacional (Dammert; Sandoval, 2019). Luego de los atentados del 11 de septiembre de 2001, en Nueva York, Chile se ha posicionado como un destino de la migración, particularmente en aquellas Sur-Sur (Godoy, 2007; Santander, 2006; Stefoni, 2005). En números absolutos, esta migración se ha cuadruplicado desde el fin de la dictadura de Pinochet (1973-1990) hasta la actualidad, y cuenta con rasgos bastante específicos debido a la fuerte presencia femenina, indígena y afrodescendiente (Tijoux; Sir-Retamales, 2015). Sin embargo, se puede observar un patrón en la última década por:1) aumento de la cantidad de migrantes; 2) diversificación de países de origen; y 3) mayor presencia de migrantes en regiones (Mundaca et al., 2018).

Más allá del evidente aumento de la población migrante, la comunidad imaginada no se sentía amenazada, y los discursos de medios de comunicación especialmente contrarios a esta población eran limitados. Sin embargo, dos hitos marcaron lo que 
la opinión pública reconoció como crisis migratoria. Primero, en agosto de 2016, el Ministerio Público abrió una investigación acerca de la eventual participación de la aerolínea chilena Latin American Wings en un caso de tráfico de migrantes, dado el masivo ingreso de ciudadanos haitianos como turistas, pero que en realidad ingresaban con fines de residencia en Chile ("Tráfico de inmigrantes...", 2017). Segundo, en julio de 2017, el Ministerio de Salud confirmó la detección, en Valdivia, de un caso de lepra en un ciudadano haitiano, enfermedad de la cual no había registros en Chile continental (Batarce, 2017).

Ambos hechos impactaron sobre la agenda pública e instalaron el tema migratorio como una preocupación social. La presidenta Michelle Bachelet (2014-2018) adoptó una política considerada de puertas abiertas hacia la migración, destacando su contribución económica y cultural a Chile. En enero de 2017, propuso reemplazar la legislación migratoria vigente desde 1975, lo que, entre otras cosas, aseguraría a los migrantes indocumentados el acceso a salud, educación, seguridad social y justicia laboral, además de disminuir las restricciones de ingreso y descriminalizar la migración irregular, permitiéndoles apelar ante una posible expulsión. Este proyecto fue rechazado por el Parlamento (Ayala; Bazán, 2017).

En este contexto, los medios de comunicación aumentaron de forma sistemática la cobertura de las noticias sobre migración. Una búsqueda a través de la plataforma de monitoreo de noticias Nexnews arroja una fluctuación más que significativa en las informaciones publicadas entre 2015 y 2018, con un total acumulando de 12195 notas a septiembre de 2018 (ver Gráfico 1).

\begin{tabular}{l|l} 
GRÁFICO 1 & $\begin{array}{l}\text { Volumen de noticias en los medios relacionadas con migración, } \\
\text { Chile 2015-2018 }\end{array}$
\end{tabular}

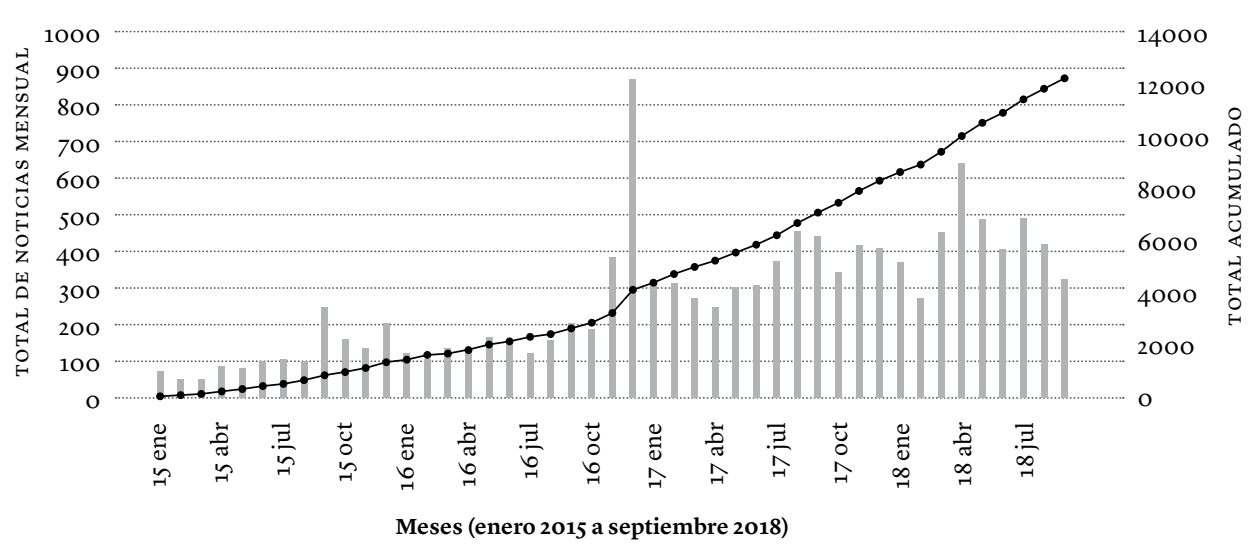


Los medios de comunicación son un canal importante en el ecosistema de fuentes de información para la ciudadanía chilena. De acuerdo con el estudio Digital News Report, $75 \%$ de la población del país consume noticias a través de la televisión; $36 \%$, por la radio; $40 \%$, por la prensa; y $89 \%$, a través de internet (Fernández-Medina, 2018). Estas cifras respaldan los hallazgos de Scherman y Etchegaray (2013), y Dammert (2012), que enfatizan el hecho de que, siendo Chile es uno de los países con menores índices de criminalidad en la región, también es uno de los que exhibe más altos niveles de temor al delito, situación que se explicaría, según los autores, por la presencia de una relación positiva entre el consumo de noticias en televisión abierta y el miedo a ser víctima de la delincuencia.

La opinión pública había ya tomado el camino de proteger lo que consideraba era su comunidad imaginada. Así, de acuerdo a la encuesta de abril-mayo de 2017 del Centro de Estudios Públicos, el $41 \%$ de la ciudadanía chilena estimaba que los extranjeros que llegaban al país para establecerse elevaban los índices de criminalidad; un $40 \%$ de los encuestados creía que los migrantes le quitaban el trabajo a los locales; $30 \%$ creía que los extranjeros empeoraban la economía chilena; $50 \%$ no estaba de acuerdo con que los migrantes legales debieran tener los mismos derechos que los ciudadanos chilenos; $57 \%$ pensaba que Chile debería tomar medidas más drásticas para excluir a los inmigrantes indocumentados; y $45 \%$ opinaba que la cultura chilena era generalmente debilitada por los extranjeros que llegaban a vivir (Dammert; Sandoval, 2019). Se establece una agenda con dos caras frente a la migración: por un lado, entendida como mano de obra barata y necesaria para el desarrollo de ciertas áreas industriales del país; por otro, como posible criminalidad, vinculada con prácticas cotidianas percibidas como violentas. Se busca desdoblar la imagen del migrante, como si esto fuera posible.

En el período electoral de 2017, la migración jugó un rol principal y fue abordado por todos los sectores políticos desde distintos ángulos. En ese marco, el actual presidente, Sebastián Piñera (2018-2021), afirmó que "muchas de las bandas de delincuentes en Chile son de extranjeros" (Carreño, 2017). Consolidando la imagen de los otros considerados principalmente peligrosos.

\section{Metodología}

Analizar la importancia y características de la cobertura de medios de prensa sobre la migración y el desarrollo del populismo punitivo en el marco de la última elección en Chile (2017) requiere de una técnica de análisis de contenidos mediante la aproximación inductiva, a partir de la escala de encuadres noticiosos de la inmigración 
(ENI), propuesta por Igartua, Muñiz y Cheng (2005), adaptada para la realidad y actualidad chilena.

Para esto, se analizaron todas las piezas informativas de las secciones Editorial, Cartas al director, Nacional, Política, Reportajes y Tendencias, en las ediciones nacionales impresas de los diarios El Mercurio y La Tercera. De acuerdo con el Boletín de Circulación y Lectura de Diarios del primer semestre de 2017 de la Asociación Chilena de Publicidad (ACHAP, 2017), los dos medios escogidos son los principales periódicos impresos del país, tanto en volumen de unidades vendidas cada día, como por alcance de lectoría (ver Cuadro 1).

CUADRO 1 Circulación y lectoría de diarios matutinos generalistas nacionales en Chile (primer semestre de 2017)

\begin{tabular}{|l|c|c|}
\hline Medio & $\begin{array}{c}\text { Promedio de circulación neta } \\
\text { semanal (unidades vendidas) }\end{array}$ & $\begin{array}{c}\text { Promedio de lectoría en Santiago } \\
\text { (personas que dicen leer periódico*) }\end{array}$ \\
\hline El Mercurio & 131961 & 294935 \\
\hline La Tercera & 78224 & 253149 \\
\hline $\begin{array}{l}\text { Las Últimas } \\
\text { Noticias }\end{array}$ & 84440 & 224906 \\
\hline La Cuarta & 68652 & 292352 \\
\hline
\end{tabular}

Fuente: adaptado de ACHAP (2017). *Según encuesta IPSOS (como se citó en ACHAP, 2017).

La investigación se desarrolló utilizando dos técnicas: por un lado, se seleccionaron seis semanas construidas empleando salto sistemático cada ocho días, partiendo de las ediciones impresas el 2 de enero de 2017, hasta las ediciones del 30 de septiembre de 2017, ambas fechas inclusive. Por otro lado, durante el período de campaña electoral se optó por una técnica de análisis censal para el lapso entre el 1 de octubre y el 31 de diciembre de 2017, es decir trece semanas.

Para asegurar fiabilidad en el proceso de codificación, se empleó a dos asistentes de investigación, quienes eran estudiantes universitarios de ciencias sociales, un hombre y una mujer, con experiencia previa en metodología de la investigación, hablantes nativos de idioma español, y de nacionalidad chilena. Se realizó un pretest con noticias sobre migración extraídas de la edición impresa del diario El Mercurio de Valparaíso, entre el 1 y el 31 de octubre de 2017. Así también, se realizaron dos reuniones de entrenamiento para los codificadores, además de otras dos para ajustes en el libro de códigos. 
A partir de las muestras recogidas, se seleccionó un $10 \%$ aleatorio de las unidades analizadas y se le reasignaron al codificador opuesto, de modo que se pudiera calcular el valor alfa de Krippendorff y Fleiss (1978) -Kalpha- a través del software SPSS v.23, utilizando la macro de Hayes y Krippendorff (2007), que arrojó un resultado de 0,812.

Los contenidos fueron codificados utilizando un libro de códigos y variables construido sobre la base de cinco dimensiones, que agrupan 45 variables: indicadores de identificación y control (11 variables); indicadores de política editorial (4 variables); indicadores de tratamiento noticioso (13 variables); ENI adaptada para Chile (13 variables); e indicadores del perfil del migrante (4 variables). Las variables utilizadas describen aspectos objetivos que aparecen en el texto de cada unidad de análisis, por lo tanto, cada una de ellas fue codificada de acuerdo con lo que la noticia informa de manera expresa, sin que los codificadores incluyan su propia interpretación.

Para efectos de este estudio, se utilizaron las categorías de encuadre propuestas por Igartua, Muñiz y Cheng (2005), adaptadas a la realidad y actualidad chilena; por ejemplo, dentro de la categoría de encuadres de inmigración se agregó un ítem particular para analizar el tratamiento noticioso sobre inmigrantes en el contexto de las elecciones presidenciales de Chile en 2017. La categoría de encuadre de inmigración se compone de cinco encuadres genéricos: situación legal, aporte económico a la sociedad, aporte cultural a la sociedad, xenofobia y debate legislativo, siendo este último un agregado a la metodología propuesta respondiendo al contexto chileno $y$, por ende, siendo un encuadre específico.

A su vez, cada categoría está construida a partir de varios ítems dicotómicos (presencia o ausencia) que permiten dilucidar el tratamiento informativo que presentó el fenómeno migratorio en la prensa local. Así, el encuadre sobre la situación legal busca observar la presencia de información sobre la situación legal del migrante, alguna relación delictual y algún interés en regularizar su residencia; el encuadre sobre el aporte económico a la sociedad pretende levantar información respecto a la situación laboral del inmigrante, su contribución a las arcas fiscales y el uso que hace de los servicios sociales que provee el Estado; el encuadre sobre aporte cultural a la sociedad involucra un análisis de la presencia de estilos de vida diferentes a los locales y la percepción de que aquellos pudieran generar una ganancia en la diversidad cultural del país; el encuadre sobre xenofobia se refiere a la cobertura dentro de las piezas noticiosas analizadas de hechos de violencia tanto física como sicológica; y el encuadre sobre el debate legislativo se refiere a la discusión respecto a la amnistía migratoria que se propuso durante la campaña política, así como la relevancia de la expulsión del país de los inmigrantes indocumentados.

El análisis descriptivo de la información sistematizada muestra algunas características interesantes. Respecto al total de semanas construidas y analizadas durante 
el 2017, la cobertura periodística sobre una temática social clave durante un año electoral muestra una tendencia a la estabilidad en el total de notas, pero variabilidad en las fuentes. De hecho, entre enero y diciembre, las piezas de noticias, que sumaron setenta, en ambos diarios presentaron una disminución (ver Gráfico 2).

GRÁFICO 2 Noticias sobre migración enero-diciembre 2017 (semanas construidas)

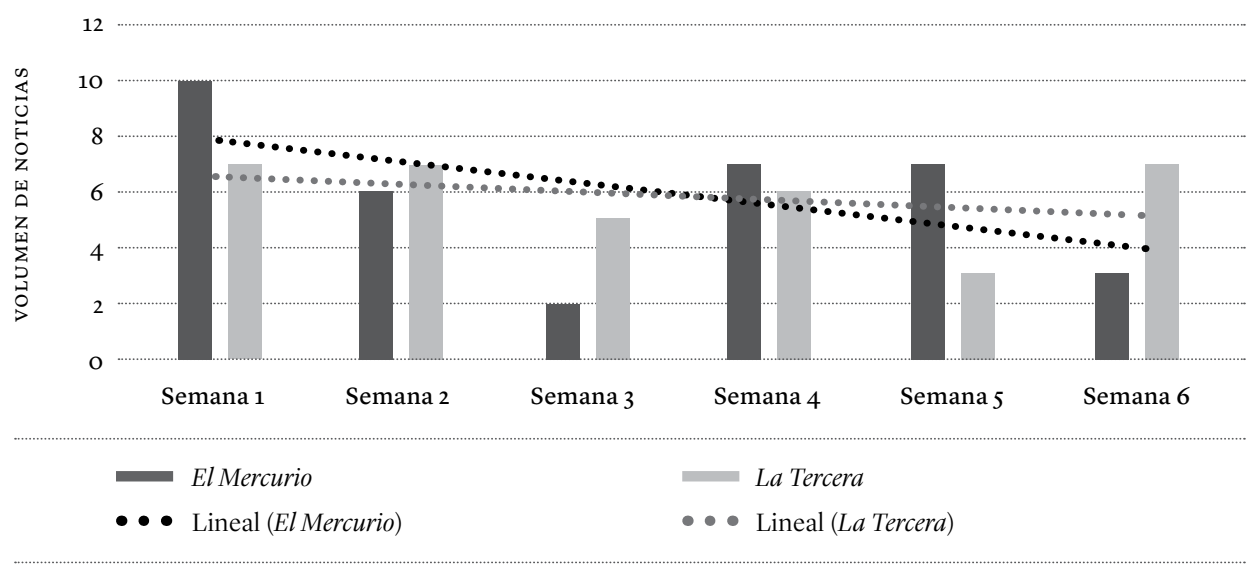

Las piezas noticiosas de la semana 1 corresponden a eventos en el marco de las vacaciones estivales de Chile, entre los meses de enero y febrero. En ese contexto, en Chile es natural que el volumen de noticias relacionadas con política o los poderes del Estado disminuyan considerablemente, en atención a que tanto los ciudadanos como los personeros de gobierno se encuentran fuera de sus funciones habituales. De las 17 noticias publicadas por El Mercurio y La Tercera en este período, seis se relacionan con tráfico de drogas, la muerte de extranjeros en Chile y la participación de migrantes en actos delictuales en torno al conflicto en la región de la Araucanía del país. En este período, aparece el problema de salud pública a enfrentar dado el déficit de profesionales de la medicina y la disminución de los extranjeros que aprueban el Examen Único Nacional de Conocimientos de Medicina.

Las noticias de la semana 2, correspondientes a los meses de marzo y abril, tienen un menor volumen de notas sobre migración y aún menor que vinculen criminalidad con migración, con seis de las trece piezas relacionadas con un incidente fronterizo con un grupo de militares bolivianos que cruzó la frontera de forma ilegal, la sustracción de un menor de edad por parte de su padre extranjero y el desbaratamiento 
de una red de prostitución y trata de personas. Llama la atención que hacia finales del período de análisis aparece la preocupación por el aumento de migrantes y los desafíos para la implementación del censo nacional. La cobertura no es solo negativa, de hecho, se reconoce el trabajo de voluntarios haitianos que ayudarán a traducir el formulario y a aplicarlo en terreno durante el operativo censal.

A pesar de que solo llegaron a sumar siete noticias en la semana construida 3 , es posible notar un aumento considerable en el tono negativo sobre los temas cubiertos, con una fuerte interpretación de amenaza hacia la sociedad local. Por ejemplo, surge por primera vez un reportaje de crónica en La Tercera donde se destaca que $40 \%$ de los chilenos cree que los migrantes le quitan el trabajo; el mismo periódico publicó en esta semana construida que casi el $40 \%$ de los inmigrantes tiene una pareja chilena, noticia que, al ser analizada en particular, resulta capciosa, puesto que el titular podría denotar que aquel hecho pone en riesgo la búsqueda de pareja de nacionalidad chilena o que eventualmente podría implicar un cambio cultural a largo plazo. Sin embargo, el encuadre que hacen los entrevistados deja en claro que el volumen de extranjeros en Chile es aún pequeño y que estas uniones matrimoniales son un ejemplo clásico de integración positiva.

Durante la semana 4, las trece notas consideradas comienzan a mostrar una preocupación más intensa por los problemas sociales que afectan a la integración de los migrantes. Siempre abultando las secciones de crónica, nacional y de opinión, los principales focos noticiosos se centran en la necesidad de enviar un proyecto de reforma a la ley de migraciones -incluyendo la derivada de una visa especial para haitianos-, y los resultados y estadísticas de quienes rindieron el Examen Único Nacional de Conocimientos de Medicina.

En la quinta semana construida, se comienza a percibir un clima noticioso de negatividad hacia los migrantes. Todas las piezas observadas en este período, que suman diez en total, corresponden a la crisis migratoria como tema central, destacando con suma relevancia la necesidad de que el Gobierno actúe de forma más rápida y eficiente en la tramitación de la reforma a la ley de migraciones. La semana 6 tiene diez notas que, si bien muestran una reducción en la mayoría de los casos, dada la coincidencia con el período de propaganda electoral, se incluyen temáticas propuestas por los candidatos. Esta coyuntura fue, además, incluida en el análisis censal.

Adicional al análisis de semanas construidas, se realizó un análisis censal entre el 2 de octubre y el 31 de diciembre de 2017 -período oficial de propaganda electoral en Chile-, organizado en trece semanas. En este período, El Mercurio publicó 77 piezas noticiosas con menciones a migrantes o a temas de migración, mientras que La Tercera sumó 92 notas (ver Gráfico 3). 
GRÁFICO 3 Noticias sobre migración octubre-diciembre 2017 (análisis censal)

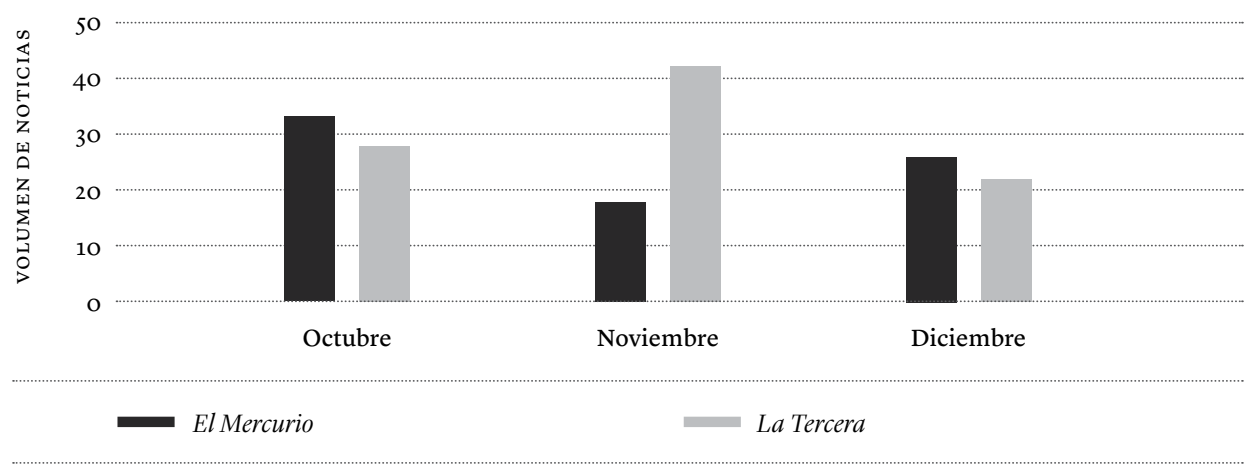

Fuente: elaboración propia.

\section{Hallazgos}

La cobertura de medios durante el año 2017, especialmente en el período de campaña electoral, reconoció en la migración una temática de relevancia. El análisis de las semanas construidas no permite definir conclusiones o avanzar en la confirmación o negación de las hipótesis de investigación propuestas. Sin embargo, permite afirmar que la migración es una temática presente en los diarios de mayor circulación y que los énfasis se articulan alrededor de hechos contingentes o preocupaciones emergentes. Es en el análisis de todo el período de campaña donde se logran encontrar señales de interpretación de la cobertura medial vinculada, además, con el énfasis político que tuvo la migración, especialmente en el debate presidencial.

De esta forma, las 175 notas periodísticas que se analizaron durante los tres meses de campaña fueron codificadas y organizadas alrededor de tres temáticas principales: política social, crimen/justicia y opinión pública. La organización de las notas incluye el objetivo principal de la noticia; así, en opinión pública se incluyen los editoriales o columnas que aparecieron en ambos diarios en las secciones analizadas, mientras que el resto de las noticias se organizan en torno al eje política social/política criminal como argumento central. Las piezas de opinión pública tuvieron una presencia constante en todo el período, con un aumento posterior a las elecciones tanto en la primera vuelta (19 de noviembre) como después de la segunda (17 de diciembre), donde se eligió a Sebastián Piñera para el período 2018-2021.

La cobertura sobre política social y justicia/crimen está presente durante todo el período analizado. Si bien ambos diarios tienen una cobertura muy similar en 
temas vinculados a la política social, la distancia se amplía sustancialmente en el área de justicia/crimen, donde La Tercera presenta casi un tercio más de noticias que El Mercurio. En ambos casos, las noticias relacionadas con la migración fueron publicadas mayoritariamente en la sección Crónica (76 \% en El Mercurio, y 61,5\% en La Tercera), seguidas de aquellas incluidas en la sección de Opinión (9,3\% en El Mercurio, y 14,3 \% en La Tercera). Sobre la nacionalidad de los migrantes mencionados en las piezas noticiosas observadas, son los haitianos quienes lideran el volumen de menciones en El Mercurio (40,5\%), mientras que en La Tercera son los venezolanos $(35,9 \%)$.

\section{¿Parte de la comunidad? Refugiados sirios y migrantes haitianos}

Al observar y comparar el tratamiento noticioso de la situación de migrantes sirios, haitianos y venezolanos, se evidencia un trato arbitrariamente distinto e incluso tendencioso. En particular, resulta interesante mirar en mayor detalle el tratamiento noticioso que se aplicó a las poblaciones de Siria y Haití. Si bien en los dos países la situación social y política es la principal razón por la que sus ciudadanos emigran, el abordaje y la manera de interpretar la llegada de dichos migrantes es diferente.

En el primer caso, la llegada se debe a un programa liderado por el Estado de Chile y la Agencia de las Naciones Unidas para los Refugiados (Naciones Unidas, 2017), a través del cual los migrantes arribaron en octubre de 2017. La noticia de la llegada de los 66 ciudadanos sirios fue cubierta como una acción de responsabilidad internacional del Estado chileno, mostrando todos los mecanismos de protección que se pusieron a disposición de las quince familias. De hecho, el 9 de octubre de 2017, el diario El Mercurio dedica un editorial titulado "Positiva acogida a refugiados sirios" (2017: A3), donde agrega que "esta vez se trata de un programa bien diseñado, con selección y exámenes médicos previos al ingreso, recursos y planes para solucionar problemas de idioma e integración”. No obstante, el mismo periódico publicó, 43 días más tarde, que los "refugiados sirios dicen sentirse inseguros y exigen salir de Chile" (González, 2017b: C12), narrando un episodio de violencia física que una mujer siria sufrió en la comuna de Macul, enfatizando que se encontraba embarazada y que un hombre intentó quitarle su velo islámico. Adicionalmente, se citan de manera indirecta reclamos de los propios refugiados, quienes "acusan falta de apoyo del programa y lentitud en el acceso a servicios como la salud” (González, 2017b: C12).

Comparativamente, el tratamiento hacia los migrantes haitianos es objetivamente diferente. En un episodio confuso que terminó con la muerte de una joven mujer migrante haitiana -llamada Joane Florvil-, el encuadre noticioso se centró inicialmente en el "presunto abandono de un menor" (González, 2017a: C7), como 
un hecho delictual cometido por la mujer, Posteriormente, y con el desarrollo de la investigación, el encuadre cambió hacia la presencia de una barrera idiomática que implicaba serias limitantes para los haitianos en su integración en Chile (Gálvez, 2017: C13). Llama la atención el énfasis puesto en la barrera idiomática cuando incluso en las mismas noticias publicadas sobre la migración siria se afirma que las nuevas unidades de apoyo creadas tienen "la finalidad de atender tanto a víctimas como a victimarios migrantes, con especial prioridad en aquellos que no tengan dominio del idioma, tales como haitianos, asiáticos o africanos" (Gálvez, 2017: C13), omitiendo que cabría la posibilidad de que ciudadanos europeos, caribeños o incluso brasileños pudieran necesitar este apoyo.

De esta forma, observamos que los migrantes sirios son reconocidos por su situación de refugio y de grupo acotado en cantidad, mientras que aquellos provenientes de Haití son siempre identificados como migrantes de profundas necesidades sociales. Si bien es posible que muchos tengan incluso situación de refugio, esta información nunca es consignada en las notas periodísticas.

\section{La amenaza: haitianos y colombianos}

La alteridad se percibe más específicamente en grupos sociales particulares cuando se trata de noticias relacionadas a salud, trabajo y seguridad. El 13 de noviembre de 2017, El Mercurio publicó una entrevista con Évelyne Trouillot, escritora y académica haitiana, destacando en su titular una declaración que, de ser leída descontextualizadamente y sin pasar inmediatamente al cuerpo de la nota, induce a creer que la migración de ciudadanos de ese país no es algo positivo para Chile: "Es una situación complicada. Haití debería ser capaz, gradualmente, de retener a sus ciudadanos” (González, 2017a: C7). Así también, el 11 de octubre de 2017, El Mercurio publicó una pequeña nota titulada "Gobierno lanza campaña contra el VIH" (2017: C12), destacando que "la iniciativa incluye afiches en creole, como una forma de que el mensaje llegue a la población haitiana en Chile" y que "el lanzamiento fue en el Liceo Bicentenario de Cerro Navia, comuna que cuenta con cerca de mil ciudadanos haitianos".

Por otro lado, el episodio protagonizado por el entonces senador y candidato a la reelección Fulvio Rossi, el 15 de noviembre de 2017, donde afirmó haber sido víctima de un ataque con arma blanca por parte de un extranjero mientras hacía campaña política en su comando en la ciudad de Iquique, se transformó en uno de los hitos más importantes en el debate migratorio. Dado que junto con el encuadre de extranjeros como personas violentas y delincuentes, el senador Rossi dijo a la prensa que "sería una persona con acento extranjero y de raza negra" (Jaime, 2017), 
se potenció un volumen de acciones legales, declaraciones en la prensa y notas periodísticas al respecto, tales como "Colectivo de migrantes llaman a descartar 'prejuicios' por caso Rossi” (Jaime; Araya; Cerda, 2017), que incluso terminó con una querella interpuesta por seis agrupaciones de inmigrantes en contra del candidato por el delito de incitación al odio ("Interponen querella...", 2017; Organizaciones migrantes denunciarán..., 2017), y con una carta al director, enviada por el embajador de Colombia en Chile a La Tercera, haciendo un llamado a no generalizar en acusaciones que afectaran a su comunidad (Echeverry-Gutiérrez, 2017). Así, el foco del debate migratorio se concentró temporalmente en la delincuencia presuntamente atribuible a inmigrantes y extranjeros en la frontera norte de Chile, vinculada a hechos delictuales como narcotráfico y sicariato.

Llaman también la atención los titulares que tienden a confundir al lector, generando un encuadre poco categórico. Por ejemplo, el 28 de noviembre, La Tercera publicó un artículo titulado "Haitianos irrumpen en mercado laboral y se acercan al $10 \%$ de empleo migrante" (Petersen, 2017), que puede ser interpretado como un hecho positivo -están encontrando puestos de trabajo en Chile-o negativo-le están quitando el trabajo a los ciudadanos chilenos-. Es preciso puntualizar que, si bien el titular de la nota se refiere a haitianos, estos recién ocupan el cuarto lugar en el ranking de procedencia de trabajadores extranjeros, superados por Perú, Colombia y Bolivia, y totalizando solamente el $5 \%$ de la fuerza laboral (Carrasco, 2017).

Similar es la nota de El Mercurio titulada "Sectores del comercio y turismo emplean al $34 \%$ de los inmigrantes en Chile", donde la bajada de la pieza noticiosa explicita que "actualmente, 64232 ocupados extranjeros trabajan en estos rubros y, de este total, 26,4 \% son peruanos, y 19,1 \%, colombianos. Estos últimos han casi triplicado su participación en el mercado en un año" (Pradel, 2017: B12). No obstante, la fotografía que se utiliza para ilustrar la noticia es de un hombre de raza negra, presumiblemente vendedor ambulante, conversando con una mujer de raza blanca. Otro ejemplo es la nota de El Mercurio titulada "Migrantes superan a sus compañeros chilenos en puntajes PSU de Ciencias y Matemáticas" (González; Herrera, 2017), que, de ser leída en el contexto de la crisis migratoria en Chile en ese momento, se podría haber deducido que los resultados analizados correspondían a los de la Prueba de Selección Universitaria (PSU) de aquel año, sin embargo, el estudio al que hace referencia El Mercurio observa datos de 2006 a 2012.

Resulta interesante también poner atención a la cobertura en medios de comunicación sobre los médicos extranjeros que rinden el Examen Único Nacional de Conocimientos de Medicina. En general, al referirse a los profesionales que buscan revalidar sus títulos para poder ejercer en Chile, el encuadre que se da es de una desproporción en ciertas nacionalidades, muchas veces enmarcándolo como una 
amenaza a la calidad profesional o a la generación de empleo para chilenos (Cabello, 2017; Hidalgo, 2017; Leiva, 2017).

\section{Crisis de Venezuela aún como tema político}

Cabe destacar que, si bien a fines del año 2017 la migración venezolana había ya aumentado sustancialmente en Chile, la cobertura mediática se concentraba en sus dimensiones políticas, posiblemente marcada por un debate interno que afectaba la elección presidencial, donde el candidato de la centro-derecha, de forma reiterada, afirmaba que el gobierno venezolano era una dictadura, y que se requería una acción política distinta a la que ese llevaba implementando, así como por una fuerte campaña de medios sociales que acuñaron el concepto de Chilezuela para generar temor en la población, estableciendo que votar por la izquierda era similar a apoyar al régimen de Maduro.

Las notas políticas resaltan la crisis institucional venezolana, en especial la situación de los magistrados que buscaron fugarse del país con la intención de llegar a Chile (Aninat, 2017; Labra, 2017; Salas, 2017; Soto, 2017). Como se puede observar, el acontecimiento fue seguido de cerca por ambos medios, y permitió evidenciar las diferentes posiciones que ambos sectores políticos del país tenían respecto al proceso venezolano.

\section{¿Reconocimiento o políticamente correcto?}

Las notas relevadas a lo largo del año 2017, incluso en el período electoral, incluyen diversas perspectivas que muestran algunos beneficios o cambios que trae la presencia de la migración en el país (Del Real, 2017; Grünewald, 2017; Navarrete; Patiño, 2017; Vedoya, 2017). Alejados del concepto de populismo punitivo, se pueden identificar contenidos que recurren a enfatizar en aquellos derechos a los que hoy los otros pueden acceder. Por ejemplo, la habilitación para ejercer el voto en las elecciones nacionales, el avance en el acceso a la salud y la educación, e incluso a la ayuda social para el acceso a vivienda (Huatay-Álvarez, 2017; Monroy, 2017).

El otro, además, puede ser bienvenido cuando genera un beneficio claro para la comunidad que nos imaginamos. Este rasgo es claro cuando las notas de prensa ponen énfasis en las ciudadanías de gracia entregadas a deportistas nacidos en el extranjero que representan al país en competencias internacionales (Monroy, 2017). De igual forma, cuando la cobertura reconoce el espacio laboral que los migrantes llegan a ocupar y que sistemáticamente es entendido como no interesante para los chilenos (Pradel, 2017). 


\section{A modo de conclusión}

La cobertura de medios, durante los períodos de campaña electoral, se vinculan principalmente a los contenidos generados por el debate político. Más allá de las hipótesis que ponen hincapié en las capacidades de los medios para instalar temáticas específicas, el estudio realizado no permite afirmar que en el caso chileno los medios de comunicación tuvieran control respecto al mensaje que emiten a través de sus piezas noticiosas, limitándose principalmente a publicar contenidos que respondan a la urgencia informativa, sin evaluar los posibles vínculos que las audiencias hagan respecto a los otros. A pesar de esto, se aprecia una cobertura diferenciada cuando se trata de migrantes afrodescendientes.

Se observa una alta presencia de cobertura de crónica, pero poco análisis (y menos autoanálisis) sobre el cambio social que implica abrir las fronteras a nuevos migrantes. Pero tal vez esto se puede explicar porque históricamente Chile no ha contado con grandes movimientos migratorios, y para 2017 el tema empezaba a ser debatido públicamente. Llama la atención la ausencia de notas sobre las experiencias anteriores de chilenos en el extranjero. La prensa parece olvidar que entre 1970 y 1990, durante la dictadura de Pinochet, más de 200 ooo chilenos se vieron forzados a dejar el país. Posiblemente, la construcción de la comunidad imaginada de ese período partía de la no inclusión de los que se fueron, como parte de lo que se definió como nación. De hecho, son pocas las voces que recalcan que el número de migrantes en Chile es significativamente menor que el número de chilenos que aún radican fuera del país.

No queda claro si son los candidatos políticos quienes levantan el tema migratorio hacia los medios o es al revés. Lo que se observa es un vínculo fuerte para generar pautas informativas y cobertura noticiosa en un tema que engancha a la ciudadanía. Este fenómeno necesita mayor estudio y utilización de herramientas metodológicas innovadoras que permitan conocer con más detalle el consumo de medios y el impacto que tienen sobre la audiencia. En una sociedad marcada por el temor y la sensación permanente de amenaza, la construcción de comunidades imaginadas cerradas y excluyentes puede ser un camino de difícil transcurso en un marco de globalización que estará indudablemente marcado por el aumento de los movimientos de personas en el planeta. 


\section{Referencias}

Altheide, David (2003). Mass Media, Crime, and the Discourse of Fear. The Hedgehog Review, 5(3), 9-26.

Anderson, Benedict (1983). Comunidades imaginadas: reflexiones sobre el origeny la difusión del nacionalismo. México: FCE.

Aninat, Catalina (12 de octubre de 2017). Canciller confirma que grupo de venezolanos buscará llegar a Chile. La Tercera, p. 15. Recuperado de https://www.latercera.com/noticia/ canciller-confirma-grupo-venezolanos-buscara-llegar-chile/

Asociación Chilena de Publicidad (2017). Boletín de circulación y lectura de diarios $10^{\circ}$ semestre 2017. Recuperado de https://www.dropbox.com/s/xh7lk39edaaojro/Boletin_de_Circulación_y_Lectura_1 ${ }^{\mathrm{O}} \_$semestre_2017.pdf?dl=0

Ayala, Leslie; Bazán, Ignacio (22 de enero de 2017). El nuevo trato que Bachelet propone a los inmigrantes. La Tercera. Recuperado de https://www.latercera.com/noticia/nuevo-trato-bachelet-propone-los-inmigrantes/

Batarce, Catalina (31 de julio de 2017). Ciudadano haitiano en Valdivia es sospechoso de padecer lepra. La Tercera. Recuperado de http://www2.latercera.com/noticia/haitiano-se-convierte-primer-caso-lepra-chile-continental/\#

Bonner, Michelle (2018). Media and Punitive Populism in Argentina and Chile. Bulletin of Latin American Research, 37(3), 275-29o. https://doi.org/10.1111/blar.12744

Bosworth, Mary (2008). Immigration Detention. Criminal Justice Matters, 71(1), 24-25. https:// doi.org/10.1080/09627250801937611

Bottoms, Anthony (1995). Philosophy and Politics of Punishment and Sentencing. En Politics of Sentencing Reform (pp. 17-49), editado por Chris Clarkson; Rod Morgan. Oxford: Clarendon Press.

Bozdağ, Çiğdem; Smets, Kevin (2017). Understanding the Images of Alan Kurdi with "Small Data": A Qualitative, Comparative Analysis of Tweets About Refugees in Turkey and Flanders (Belgium). International Journal of Communication, 11, 4046-4069.

Breuilly, John (2016). Benedict Anderson's Imagined Communities: A Symposium. Nations and Nationalism, 22(4), 625-659. https://doi.org/10.1111/nana.12236

Brouwer, Jelmer; Van der Woude, Maartjie; Van der Leun, Joanne (2017). Framing Migration and the Process of Crimmigration: A Systematic Analysis of the Media Representation of Unauthorized Immigrants in the Netherlands. European Journal of Criminology, 14(1), 100-119. https://doi.org/10.1177/1477370816640136 
Cabello, Nadia (7 de noviembre de 2017). Hospitales tienen 834 médicos extranjeros y $77 \%$ son venezolanos. El Mercurio, p. C8. Recuperado de http://www.economiaynegocios.cl/ noticias/noticias. asp $? \mathrm{id}=414806$

Calhoun, Craig (2016). The Importance of Imagined Communities - and Benedict Anderson. DEBATS: Journal on Culture, Power and Society, 1, 11-16.

Calhoun, Craig (2017). Populism, Nationalism and Brexit. En Brexit: Sociological Responses (pp. 57-76), editado por William Outhwaite. Londres: Anthem Press.

Carrasco, Pamela (22 de octubre de 2017). El $5 \%$ de la fuerza laboral es extranjera. El Mercurio, p. 2. Recuperado de http://www.economiaynegocios.cl/noticias/noticias.asp?id=409534

Carreño, Camilo (29 de noviembre de 2017). Piñera: "Muchas de las bandas de delincuentes en Chile son de extranjeros". La Tercera. Recuperado de http://www2.latercera.com/noticia/ pinera-muchas-las-bandas-delincuentes-chile-extranjeros/

Chacón, Jennifer (2012). Overcriminalizing Immigration. The Journal of Criminal Law \& Criminology, 102(3), 613-652.

Cuevas-Calderón, Elder Alejandro (2019). Reconfiguración social entre la migración y la percepción inseguridad en Lima, Perú. URVIO: Revista Latinoamericana de Estudios de Seguridad, 23, 73-90.

Dammert, Lucía (2012). Fear and Crime in Latin America: Redefining State-Society Relations. Abingdon: Routledge.

Dammert, Lucía (2019). Police Reform in Latin America? En Handbook of Law and Society in Latin America (pp. 259-277), editado por Rachel Sieder; Karina Ansolabehre; Tatiana

A. Alfonso-Sierra. New York: Routledge.

Dammert, Lucía; Sandoval, Rodrigo (2019). Crimen, inseguridad y migración: de la percepción a la realidad. En Migración en Chile, evidencia y mitos de una nueva realidad (pp. 199-230), editado por Nicolás Rojas-Pedemonte; José Tomás Vicuña. Santiago de Chile: LOM.

Danso, Ransford; McDonald, David (2001). Writing Xenophobia: Immigration and the Print Media in Post-Apartheid South Africa. Africa Today, 48(3), 115-137.

Dayan, Daniel; Katz, Elihu (1992). Media Events. Cambridge, MA: Harvard University Press.

De Cillia, Rudolf; Reisigl, Martin; Wodak, Ruth (1999). The Discursive Construction of National Identities.Discourse o Society,10(2),149-173.https://doi.org/10.1177/0957926599010002002

De Raadt, Jasper; Hollanders, David; Krouwel, André (2004). Varieties of Populism: An Analysis of the Programmatic Character of Six European Parties. Inédito. 
Del Real, Andrés (14 de diciembre de 2017). El fenómeno migratorio se toma los festivales chilenos. La Tercera, p. 42. Recuperado de https://culto.latercera.com/2017/12/13/fenomeno-migratorio-se-toma-los-festivales-chilenos/

Desai, Radhika (2008). Review Essay: The Inadvertence of Benedict Anderson: A Review Essay of Imagined Communities on the Occasion of a New Edition. Global Media and Communication, 4(2), 183-20o. https://doi.org/10.1177/1742766508091519

Dobrynina, Margarita (2016). The Roots of "Penal Populism": The Role of Media and Politics, Kriminologijos Studijos, 4, 98-124. https://doi.org/10.15388/CrimLithuan.2016.4.10729

Doob, Leonard (1965). Psychology in the African World. En African World: A Survey of Social Research (pp. 37-52), editado por Robert Lystad. Nueva York: Proaeger.

Echeverry-Gutiérrez, Mauricio (18 de noviembre de 2017). Agresión al senador Rossi. La Tercera, p.16. Recuperado de https://www.latercera.com/noticia/agresion-al-senador-rossi/

Ericson, Richard (2007). Crime in an Insecure World. Cambridge: Polity Press.

Fernández-Medina, Francisco (2018). Chile. En Reuters Institute Digital News Report 2018 (pp. 120-122), editado por Nic Newman; Richard Fletcher; Antonis Kalogeropoulos; David A. L. Levy; Rasmus Kleis Nielsen. Oxford: Reuters Institute for the Study of Journalism.

Finlayson, Alan (2001). Imagined Communities. En The Blackwell Companion to Political Socio$\log y$ (pp. 281-290), editado por Kate Nash; Alan Scott. Malden, MA: Blackwell Publishing.

Focas, Brenda; Kessler, Gabriel (2015). Inseguridad y opinión pública: debates y líneas de investigación sobre el impacto de los medios. Revista Mexicana de Opinión Pública, 19, 41-59.

Galtung, Johan; Ruge, Mari Holmboe (1965). The Structure of Foreign News: The Presentation of Congo, Cuba and Cyprus in four Norwegian Newspapers. Journal of Peace Research, 2(1), 64-9o. https://doi.org/10.1177/002234336500200104

Gálvez, Mario (13 de octubre de 2017). Carabineros instala subcomisaría en Conchalí que atenderá a los inmigrantes. ElMercurio, p. C13. Recuperado de http://www.economiaynegocios. $\mathrm{cl} /$ noticias/noticias.asp?id=406809

Gasper, Des; Sinatti, Giulia (2016). Una investigación sobre migración en el marco de la seguridad humana. Migración y desarrollo, 14(27), 19-63.

Gerard, Alison; Pickering, Sharon (2013). Crimmigration: Criminal Justice, Refugee Protection and the Securitisation of Migration. En The Routledge Handbook of International Crime and Justice Studies (pp.587-611), editado por Bruce Arrigo; Heather Bersot. Abingdon: Routledge.

Gobierno lanza campaña contra el VIH (11 de octubre de 2017). El Mercurio, p. C12. Recuperado de https://www.emol.com/noticias/nacional/2005/10/05/197382/gobierno-lanza-polemica-campana-contra-el-sida.html 
Godoy, Lorena (2007). Fenómenos migratorios y género: identidades 'remodeladas'. Psykhe, 16(1), 41-51. http://doi.org/10.4067/So718-22282007000100004

González, Valentina (13 de noviembre de 2017a). Es una situación complicada. Haití debería ser capaz, gradualmente, de retener a sus ciudadanos. El Mercurio, p. C7. Recuperado de http://www.economiaynegocios.cl/noticias/noticias.asp?id=416740

González, Valentina (24 de noviembre de 2017b). Refugiados sirios dicen sentirse inseguros y exigen salir de Chile. El Mercurio, p. C12. Recuperado de http://www.economiaynegocios. $\mathrm{cl} /$ noticias/noticias.asp?id=419861

González, Valentina; Herrera, Judith (29 de noviembre de 2017). Migrantes superan a sus compañeros chilenos en puntaje PSU de Ciencias y Matemáticas. El Mercurio, p. C1. Recuperado de http://www.economiaynegocios.cl/noticias/noticias.asp?id=421293

Graber, Doris (1980). Crime News and the Public. Nueva York: Praeger.

Granero, María Georgina (2018). Análisis de modalidades identitarias en un contexto de migración. Migraciones, 44, 63-89. https://doi.org/10.14422/mig.i44.y2018.003.

Green, David A. (2008). Suitable vehicles: Framing Blame and Justice when Children Kill a Child. Crime, Media, Culture, 4(2), 197-220. https://doi.org/10.1177/1741659008092328

Grünewald, Federico (4 de noviembre de 2017). Las migraciones están cambiando el ánimo y los colores de Chile. El Mercurio, p. 4. Recuperado de http://www.economiaynegocios.cl/ noticias/noticias.asp?id $=413598$

Hayes, Andrew; Krippendorff, Klaus (2007). Answering the Call for a Standard Reliability Measure of Coding Data. Communication Methods and Measures, 1(1), 77-89. https://doi. org/10.1080/19312450709336664

Hayward, Keith; Young, Jock (2004). Cultural Criminology: Some Notes on the Script. Theoretical Criminology, 8(3), 259-273. https://doi.org/10.1177/1362480604044608

Hidalgo, Florencia (13 de noviembre de 2017). Colombianos se vuelven los médicos extranjeros más numerosos del país. La Tercera, pp. 40-41. Recuperado de https://www.latercera. com/noticia/colombianos-se-vuelven-los-medicos-extranjeros-mas-numerosos-del-pais/

Huatay-Álvarez, Carolina (5 de noviembre de 2017). Aumento de migrantes habilitados para sufragar. El Mercurio, p. A2. Recuperado de https://www.elmercurio.com/ blogs/2017/11/o5/55496/Aumento-de-migrantes-habilitados-para-sufragar.aspx

Igartua, Juan; Muñiz, Carlos; Cheng, Lifen (2005). Inmigración en la prensa española: aportaciones empíricas y metodológicas desde la teoría del encuadre noticioso. Migraciones, $17,143-181$. 
Interponen querella contra el senador Fulvio Rossi (26 de noviembre de 2017). El Mercurio, p. C2O.

Jaime, David (16 de noviembre de 2017). Gobierno y Senado se querellan por ataque al senador Fulvio Rossi al interior de su comando en Iquique. El Mercurio, p. C1.

Jaime, David; Araya, Ximena; Cerda, Claudio (17 de noviembre de 2017). "No hemos podido establecer la presencia de una persona con las características señaladas". ElMercurio, p. C1o.

Kanno, Yasuko; Norton, Bonny (2003). Imagined Communities and Educational Possibilities: Introduction. Journal of Language, Identity \& Education, 2(4), 241-249. https://doi. org/10.1207/S15327701JLIE02O4_4

Kessler, Gabriel (2009). El sentimiento de inseguridad: sociología del temor al delito. Buenos Aires: Siglo XXI.

Kim, Jeesun; Wanta, Wayne (2018). News Framing of the U.S. Immigration Debate During Election Years: Focus on Generic Frames. The Communication Review, 21(2), 89-115. https:// doi.org/10.1080/10714421.2018.1479616

Koh, Aaron (2005). Imaging the Singapore "Nation" and "Identity": The Role of the Media and National Education. Asia Pacific Journal of Education, 25(1), 75-91. https://doi. org/10.1080/02188790500032566

Krippendorff, Klaus; Fleiss, Joseph (1978). Reliability of Binary Attribute Data. Biometrics, 34(1), 142-144.

Labra, Alberto (11 de octubre de 2017). Venezolanos asilados por Chile viajan a Colombia. La Tercera, p. 11 .

Leiva, Lorena (3 de noviembre de 2017). Eunacom de diciembre contará con cifra récord de médicos inscritos. La Tercera, p. 16.

Li, Peter (2003). Initial Earnings and Catch-Up Capacity of Immigrants. Canadian Public Policy, 29(3), 319-337.

Lissovsky, Mauricio; De Matos, Marcus (2018). The Laws of Image-Nation: Brazilian Racial Tropes and the Shadows of the Slave Quarters. Law and Critique, 29(2), 173-200. https:// doi.org/10.1007/s10978-018-9222-2

Lomnitz, Claudio (2001). Deep Mexico, Silent Mexico: An Anthropology of Nationalism. Minneapolis, MN: University of Minnesota Press.

Madianou, Mirca (2002). Mediating the Nation: News, Audiences and Identities in Contemporary Greece [Tesis de doctorado]. The London School of Economics and Political Science, Londres, Inglaterra. 
Martín-Barbero, Jesús (1993). De los medios a las mediaciones: comunicación, culturay hegemonía. Barcelona: Gustavo Gili.

Melella, Cecilia (noviembre, 2011). Migraciones, medios de comunicación y construcción de identidades: El caso del periódico Renacer. Trabajo presentado en VI Jornadas de Jóvenes Investigadores, Buenos Aires, Argentina.

Minnaar, Anthony; Hough, Michael; De Kock, Chris Paul (1996). Who Goes There? Perspectives on Clandestine Migration and Illegal Aliens in Southern Africa. Pretoria: HRSC Publ.

Monroy, Eduardo (12 de noviembre de 2017). La historia del rey de las pesas cubanas que ahora disputará medallas para Chile. El Mercurio, p. D13. Recuperado de http://www.economiaynegocios.cl/noticias/noticias.asp?id $=416280$

Mountz, Alison (2010). Seeking Asylum: Human Smuggling and Bureaucracy at the Border. Minneapolis, MN: University of Minnesota Press.

Mundaca, Rodrigo; Fernández, Nicolás; Vicuña, José Tomás (2018). Migración en Chile. Un análisis desde el Censo 2017. Recuperado de http://www.sjmchile.org/wp-content/ uploads/2018/11/migracion-en-chile-un-analisis-desde-el-censo-2017-sjm.pdf

Naciones Unidas (2017). Chile acoge a 66 refugiados de Siria. Recuperado de https://news. un.org/es/story/2017/10/1387851

Nagarajan, Chitra (20 de septiembre de 2013). How Politicians and the Media Made Us Hate Immigrants. Open Democracy. Recuperado de https://www.opendemocracy.net/transformation/chitra-nagarajan/how-politicians-and-media-made-us-hate-immigrants

Nash, Kate; Alan Scott (2008). The Blackwell Companion to Political Sociology. Oxford, UK: John Wiley \& Sons.

Navarrete, María; Patiño, Paula (20 de noviembre de 2017). Haitiano se vuelve héroe al salvar a mujer que se lanzó de noveno piso. La Tercera, p. 62. Recuperado de https://www.latercera. com/noticia/haitiano-se-vuelve-heroe-al-salvar-mujer-se-lanzo-noveno-piso/

Organizaciones migrantes denunciarán por Ley Zamudio al senador Fulvio Rossi (20 de noviembre de 2017). La Tercera, p. 61.

Östgaard, Einar (1965). Factors Influencing the Flow of News. Journal of Peace Research, 2(1), 39-63. https://doi.org/10.1177/002234336500200103

Ostiguy, Pierre (2009). The High and the Low in Politics: A Two-Dimensional Political Space for Comparative Analysis and Electoral Studies. Recuperado de https://kellogg.nd.edu/sites/ default/files/old_files/documents/36o_o.pdf

Parekh, Bhikhu (1995). The Concept of National Identity. Journal of Ethnic and Migration Studies, 21(2), 255-268. https://doi.org/10.1080/1369183X.1995.9976489 
Parkin, Joanna (2013). The Criminalization of Migration in Europe: A State-Of-The-Art of the Academic Literature and Research. Liberty and Security in Europe Papers, 61. Recuperado de https://ssrn.com/abstract=2350119

Petersen, Víctor (28 de noviembre de 2017). Haitianos irrumpen en mercado laboral y se acercan al 10\% de empleo migrante. La Tercera, p. 22. Recuperado de https://www.latercera. com/noticia/haitianos-irrumpen-mercado-laboral-se-acercan-al-10-empleo-migrante/

Philo, Greg; Briant, Emma; Donald, Pauline (2013). The Role of the Press in the War on Asylum. Race or Class, 55(2), 28-41. https://doi.org/10.1177/0306396813497873

Positiva acogida a refugiados sirios (9 de octubre de 2017). El Mercurio, p. A3. Recuperado de https://www.latercera.com/noticia/positiva-acogida-refugiados-sirios/

Pradel, Daniel (29 de noviembre de 2017). Sectores del comercio y turismo emplean al $34 \%$ de los inmigrantes en Chile. El Mercurio, p. B12. Recuperado de http://www.economiaynegocios.cl/noticias/noticias.asp?id $=421285$

Pratt, John (2007). Penal Populism. Londres: Routledge.

Pyszczek, Oscar Luis (2012). The Subjetive Spaces of Fear: Construction of the Spatial Stigmatization with Respect to Urban Criminal Insecurity. Cuadernos de Geografia, 21(1), 41-54.

Salas, María (20 de octubre de 2017). "No nos imaginamos nunca la magnitud de la persecución que viviríamos". La Tercera, p. 43.

Sanjinés, Juan (2007). The Nation: An Imagined Community? Cultural Studies, 21(2-3), 295-308.

Santamaría-Lorenzo, Enrique (2002). Inmigración y barbarie: la construcción social y política del inmigrante como amenaza. Papers: Revista de Sociología, 66, 59-75. https://doi.org/ 10.5565/rev/papers/v66no.1621

Santander, Carlos (2006). La migración peruana en el contexto del patrón de las corrientes migratorias en Chile: pasado, presente y futuro. Trabajo presentado en LASA Congress, San Juan, Puerto Rico.

Scherman, Andrés; Etchegaray, Nicolle (2013). Consumo de noticias y temor al delito en Chile. Estudios sobre elmensaje periodistico, 19(1), 563-575. https://doi.org/10.5209/rev_ESMP.2013. v19.n1.42539

Slone, Michelle (2000). Responses to Media Coverage of Terrorism. Journal of Conflict Resolution, 44(4), 508-522. https://doi.org/10.1177/0022002700044004005

Smolej, Mirka; Kivivouri, Janne (2008). Crime News Trends in Finland: A Review of Recent Research. Journal of Scandinavian Studies in Criminology and Crime Prevention, 9(2), 202219. https://doi.org/10.1080/14043850802478956 
Sonderegger, Melba (2017). El papel de la cultura popular en la construcción de la identidad nacional mexicana: los fandangos jarochos. Revista Latino-Americana de Estudos em Cultura e Sociedade, 3. http://dx.doi.org/10.23899/relacult.v3i3.599

Soriano-Gatica, Juan Pablo; Peres-Neto, Luiz (2008). El discurso sobre las “pandillas latinas” en la prensa española y su impacto en la respuesta político-criminal. Famecos, 37, 5-12.

Soto, Jaime (20 de octubre de 2017). Magistrados venezolanos fueron recibidos por canciller Muñoz. El Mercurio, p. C1o.

Spena, Alessandro (2014). Iniuria Migrandi: Criminalization of Immigrants and the Basic Principles of the Criminal Law. Criminal Law and Philosophy, 8(3), 635-657. https://doi. org/10.1007/s11572-013-9229-6

Stefoni, Carolina (2005). Inmigrantes transnacionales: la formación de comunidades y la transformación en ciudadanos. En El quinto suyo: transnacionalidady formación diaspórica en la migración peruana (pp. 261-289), editado por Ulla Berg; Karsten Paerregaard. Lima: Instituto de Estudios Peruanos.

Stumpf, Juliet (2006). The Crimmigration Crisis: Immigrants, Crime, and Sovereign Power. American University Law Review, 56 (2), 367-419.

The Migration Observatory (2013). Migration in the News: Portrayals of Immigrants, Migrants, Asylum Seekers and Refugees in National British Newspapers, 2010-2012. Recuperado de https://migrationobservatory.ox.ac.uk/wp-content/uploads/2016/o4/Report-Migration_News.pdf

Thompson, John (2012). Media \& Politics. En The Wiley Blackwell Companion to Political Sociology (pp. 263-272), editado por Edwin Amenta; Kate Nash; Alan Scott. Nueva York: Blackwell Publishing Ltd.

Tijoux, María; Sir-Retamales, Hugo (2015). Trayectorias laborales de inmigrantes peruanos en Santiago: el origen de excepción y la persistencia del 'lugar aparte'. Latin American Research Review, 50 (2), 135-153.

Tráfico de inmigrantes: por qué el Gobierno acusa a LAW y cómo se defiende la aerolínea (15 de febrero de 2017). Emol.com. Recuperado de https://www.emol.com/noticias/Nacional/2017/o2/15/845160/De-que-acusa-el-Gobierno-a-la-aerolinea-Law-y-como-sedefiende.html

Treviño-Rangel, Javier; Hammeken, Pablo (2008). Racismo y nación: comunidades imaginadas en México. Estudios Sociológicos, 26(78), 669-694.

Triandafyllidou, Anna (1998). National Identity and the 'Other'. Ethnic and Racial Studies, 21(4), 593-612. https://doi.org/10.1080/014198798329784 
Tyler, Tom; Boeckmann, Robert (1997). Three Strikes and You Are Out, but Why? The Psychology of Public Support for Punishing Rule Brakers. Law \& Society Review, 31(2), 237.

Uribe-Alvarado, Ana Bertha (2005). México imaginado: recepción cultural, telenovelas e inmigrantes. Estudios sobre las culturas contemporáneas, 21, 9-33.

Vedoya, Sebastián (19 de diciembre de 2017). Encuesta revela alta valoración al trabajador migrante. La Tercera, p. 27. Recuperado de https://www.latercera.com/noticia/encuesta-revela-alta-valoracion-al-trabajador-migrante/ 